\title{
Nuclear bcl10 expression characterizes a group of ocular adnexa MALT lymphomas with shorter failure-free survival
}

\author{
Renato Franco ${ }^{1}$, Francisca I Camacho ${ }^{2}$, Alessia Caleo ${ }^{3}$, Stefania Staibano ${ }^{3}$, Delfina Bifano ${ }^{3}$, \\ Amalia De Renzo ${ }^{4}$, Fausto Tranfa ${ }^{5}$, Anna De Chiara ${ }^{1}$, Gerardo Botti ${ }^{1}$, Roberta Merola ${ }^{6}$, \\ Ana Diez ${ }^{7}$, Giulio Bonavolontà ${ }^{5}$, Gaetano De Rosa ${ }^{3}$ and Miguel A Piris ${ }^{2}$ \\ ${ }^{1}$ Pathology Unit, National Cancer Institute 'Giovanni Pascale', Naples, Italy; ${ }^{2}$ Lymphoma Group, Molecular \\ Pathology Programme, Centro Nacional de Investigaciones Oncológicas, Madrid, Spain; ${ }^{3}$ Biomorphological \\ and Functional Sciences Department, 'Federico II' University, Naples, Italy; ${ }^{4}$ Hematology Institute, 'Federico \\ II' University, Naples, Italy; ${ }^{5}$ Ophthalmology Department, 'Federico II' University, Naples, Italy; ${ }^{6}$ Clinical \\ Pathology and Cytogenetics Unit, 'Regina Elena' Cancer Institute, Rome, Italy and ${ }^{7}$ Immunohistochemistry \\ and Histology Unit, Biotechnology Programme, Centro Nacional de Investigaciones Oncológicas, Madrid, Spain
}

\begin{abstract}
Ocular adnexa B-cell lymphomas are a relatively rare group of extranodal lymphomas, marginal-zone B-cell lymphomas of mucosa-associated lymphoid tissue (MALT lymphomas) being the most frequent type at this location. As with other nongastrointestinal MALT lymphomas, ocular adnexa MALT lymphomas have distinct characteristics from those of the gastric MALT model, implying specific pathogenic events, which could be of interest in the prediction of clinical behavior and the choice between therapeutic options. In a series of 39 cases of ocular adnexa MALT lymphomas, studied using a tissue microarray, we observed that the most frequent alteration was related to apoptosis regulation. Thus, caspase 3 activity was completely abolished, and phosphorylated $I \kappa B \alpha$, a marker of NF- $k B$ activation, showed increased expression, while cases with an increased number of large cells displayed increased expression of survivin and other cell-cycle-related proteins, such as cyclin A, cyclin E and Ki67, and p16 expression was reduced. There were no occurrences of $t(11 ; 18)(q 21, q 21)$, while $5 / 37$ cases exhibited $t(14 ; 18)(q 32 ; q 21)$. Aberrant nuclear expression of bcl10 was observed in 11 cases, independently of the presence of translocations, and was significantly associated with phosphorylated $I_{\kappa} \mathrm{B} \alpha$ expression and a reduced TdT-mediated biotin-dUTP nicked-end labeling apoptotic index. Moreover, patients with tumoral bcl10 nuclear expression showed shorter failure-free survival.
\end{abstract}

Modern Pathology (2006) 19, 1055-1067. doi:10.1038/modpathol.3800597; published online 28 April 2006

Keywords: bcl10; ocular adnexa MALT Iymphomas; $t(11 ; 18)(q 21 ; q 21) ; t(14 ; 18)(q 21 ; q 32)$

Ocular adnexa B cell lymphomas (OABLs) feature a variety of different histological types, the most frequently diagnosed being extranodal marginalzone lymphoma of mucosa-associated lymphoid tissue (MALT lymphoma). ${ }^{1-6}$

Lymphomagenesis is driven by multiple accumulated genetic abnormalities that determine the survival of neoplastic cells and involve mainly cell-cycle and apoptotic pathways. ${ }^{7}$ MALT lymphomas in particular are a paradigm of alternative

Correspondence: Dr FI Camacho, MD, PhD, Lymphoma Group, Molecular Pathology Programme, Centro Nacional de Investigaciones Oncológicas, C/Melchor Fernández Almagro, 3, Madrid 28029, Spain.

E-mail: fcamacho@cnio.es

Received 24 October 2005; revised 24 February 2006; accepted 27 February 2006; published online 28 April 2006 genetic events, involving different chromosomal aberration and/or apoptosis control protein expression, leading to the deregulation of apoptotic pathways through the activation of the NF- $\kappa$ B pathway. ${ }^{7,8}$

In general, MALT lymphomas at different extranodal locations share some common morphological, phenotypic and molecular features, which has led to the establishment of gastric MALT lymphoma as the prototype for the definition of the features of MALT lymphoma at different sites. ${ }^{9,10}$ Nevertheless, there is increasing evidence to suggest that cases diagnosed with MALT lymphomas arising at different sites differ in the presence of infectious specific antigens-Helicobacter, Campylobacter, Borrelia, Chlamydia-promoting lymphoid cell proliferation, and in the frequency of chromosomal translocations such as $\mathrm{t}(11 ; 18)(\mathrm{q} 21 ; \mathrm{q} 21)$, or the newly described $\mathrm{t}(14 ; 18)(\mathrm{q} 32 ; \mathrm{q} 21)$ and $\mathrm{t}(3 ; 14)(\mathrm{p} 14.1 ; \mathrm{q} 32) .{ }^{10-12}$ 
As in the case of other extranodal lymphomas, most MALT lymphomas arising in the ocular adnexa have an indolent course with a favorable prognosis; $;^{1,2}$ previous reports have demonstrated low local aggressivity with a reasonably good possibility of relapse control by radiotherapy. ${ }^{13}$ This is in keeping with the findings from a large series of MALT lymphomas, which showed that the efficacy of treatment varied accordingly with the site, stage, and clinical status of patients. ${ }^{14}$ Nevertheless, a subset of these tumors shows a higher incidence of local or distant relapses, or even of systemic progression. ${ }^{14-16}$ Whether this can be explained in terms of the site of origin or the biological features of the tumoral cells is a matter of debate ${ }^{16}$ whose resolution requires further research.

Recent studies concur in that it is possible to associate the clinical outcome of lymphoma patients with multiple biological features defined using cDNA, oligonucleotide or tissue microarrays. ${ }^{17-20}$ The use of tissue microarrays could be particularly useful in this context, since tumoral specimens in ocular adnexa lymphomas are frequently small, fully embedded in paraffin, and require microdissection or tissue-core selection to guarantee that the analysis reports on the features of the tumoral cells.

In order to elucidate the biology of ocular adnexa MALT lymphomas we have analyzed a tissue microarray including a large series of 39 cases with a panel of antibodies and probes directed against molecules known to be involved in B-cell differentiation, cell cycle and apoptosis control, ${ }^{17-20}$ and, for control purposes, compared them with some non-MALT lymphomas from the same anatomical region. Moreover, we have included in the analysis a tissue-microarray in situ hybridization study of the apoptotic index (TdT-mediated biotin-dUTP nickedend labeling (TUNEL)), and of $\mathrm{t}(11 ; 18)(\mathrm{q} 21 ; \mathrm{q} 21)$ and $\mathrm{t}(14 ; 18)(\mathrm{q} 32 ; \mathrm{q} 21)$, which are characteristic translocations of MALT lymphomas. We have compared our results with the clinical data and the follow-up of the series, in order to establish associations between these biological characteristics and the outcome.

\section{Materials and methods}

\section{Selection of Cases}

Thirty-nine cases of MALT OABLs were collected from the Department of Pathology of 'Federico II' University. The cases, diagnosed between 1980 and 2003, were included in this study on the basis of the availability of diagnostic paraffin blocks that were thick enough to provide a minimum of 50 sections, and of clinical information for more than 6 months following diagnosis.

All cases were reviewed according to WHO classification criteria, using standard tissue sections and immunohistochemical slides.
A smaller group of non-MALT lymphomas, which are very infrequent in this anatomical region was also included in the study. It was comprised of four diffuse large B-cell lymphoma cases, three cases of follicular lymphoma (one grade 2, and two grade 3 ) and one case of Burkitt's lymphoma.

Each case of MALT OABL was subgrouped according to the cell type prevalent in the marginal-zone type (monocytoid or centrocyte type) and plasmacytoid. The prevalence of plasmacytoid cells was recorded if they represented more than $50 \%$ of neoplastic cells. Moreover, as with the histological progression in the gastric model, the presence of large cells was recorded for each case as absent/rare $(<5 \%)$, numerous $(5-10 \%$ of the neoplastic population), or with clusters of large cells (>20 cells). ${ }^{21}$

\section{Tissue-Microarray Design}

Following conventional protocols we used a tissuemicroarray device (Beecher Instruments, Sun Prairie, WI, USA) to construct a single-tissue-microarray block of 96 cores. All cases of the MALT and nonMALT lymphoma groups were histologically reviewed. The tumor-cell-rich areas, which were also representative of the presence of large cells, were marked in the paraffin blocks. Two selected 1-mm cores from different areas were included, along with two separate reactive tonsil tissues as a control to ensure the quality, reproducibility and homogeneous staining of slides. ${ }^{17-20}$

\section{Immunohistochemical Study}

Immunohistochemical staining was performed on selected proteins involved in B-cell differentiation and in cell cycle and apoptosis regulation in lymphomagenesis.

Stained tissue-microarray sections were evaluated by four different pathologists (RF, AC, DB, SS) using uniform criteria. Discrepancies were resolved through simultaneous inspection and discussion of the results. Single-marker expression was recorded as negative/positive and high/low-level, after consideration of the expression in reactive compared with tumoral cells and the specific cut-off of each marker. Details of cutoffs used for each marker are presented in Table 1.

As proposed, cytoplasmic bcl10 expression was scored as strong when it was similar to tonsil centroblast positivity, moderate when similar to centrocyte positivity, and weak/absent when similar to tonsil mantle-zone positivity. ${ }^{22}$ Nuclear positivity was also recorded. Phosphorylated $\mathrm{I} \kappa \mathrm{B} \alpha(\mathrm{p}-\mathrm{I} \kappa \mathrm{B} \alpha)$, considered to be an indirect expression of NF- $\kappa \mathrm{B}$ activity, was considered positive when expressed in the cytoplasm and the nucleus.

Discrepancies between two cores from the same case were resolved in a joint analysis of the two cores. 
Table 1 Characteristics of antibodies

\begin{tabular}{|c|c|c|c|c|c|c|}
\hline Antigen & Clone & Source & Dilution & Reactivity & Threshold & Internal control \\
\hline $\mathrm{Bcl} 2$ & 124 & DAKO & $1: 25$ & High/low & $>50 \%$ neoplastic cell & Small lymphocyte \\
\hline Bax & Polyclonal & Santa Cruz & $1: 1000$ & Positive/negative & $>10 \%$ neoplastic cell & Benign small lymphocyte \\
\hline Bcl- $\mathrm{X}_{\mathrm{L}}$ & $2 \mathrm{H} 12$ & Zymed & $1: 10$ & High/low & $>10 \%$ neoplastic cells & TMA controls \\
\hline Survivin & Polyclonal & RD System & $1: 1500$ & High/low & $>10 \%$ neoplastic cells & TMA controls \\
\hline Caspase-3 & C92-605 & PharMingen & $1: 25$ & Positive/negative & $\begin{array}{l}>10 \% \text { positive neoplastic } \\
\text { cells }\end{array}$ & TMA controls \\
\hline Bcl10 & 331.3 & Santa Cruz & $1: 1000$ & Positive/negative & $>10 \%$ neoplastic cells & Reactive lymphocyte \\
\hline MUM1 & Polyclonal & Santa Cruz & $1: 200$ & High/low & $>80 \%$ positive cells & Plasma cells \\
\hline Bcl6 & PG-B6p & DAKO & $1: 10$ & Positive/negative & $>10 \%$ neoplastic cells & GC (germinal center) B cells \\
\hline CD38 & Vs38 & DAKO & $1: 25$ & High/low & $>80 \%$ positive cells & Plasma cells \\
\hline CD5 & $4 \mathrm{C} 7$ & Novocastra & $1: 50$ & Positive/negative & $>10 \%$ positive cells & Reactive lymphocyte \\
\hline CD10 & $56 \mathrm{C} 6$ & Novocastra & $1: 10$ & Positive/negative & Any tumoral cell positive & GC B cells \\
\hline CD20 & $\mathrm{L}-26$ & DAKO & $1: 100$ & Positive/negative & $\begin{array}{l}\text { Any positive neoplastic } \\
\text { cells }\end{array}$ & Reactive lymphocyte \\
\hline Cyclin A & 6E6 & Novocastra & $1: 100$ & Positive/negative & $>10 \%$ neoplastic cells & Proliferating cells (G2/M) \\
\hline Cyclin B1 & 7A9 & Novocastra & $1: 25$ & Positive/negative & $>10 \%$ positive cells & Proliferating cells (G2/M) \\
\hline Cyclin D1 & DCS-6 & DAKO & $1: 100$ & Positive/negative & $\begin{array}{l}\text { Any positive neoplastic } \\
\text { cell }\end{array}$ & $\begin{array}{l}\text { Macrophage and endothelial } \\
\text { cells }\end{array}$ \\
\hline Cyclin D3 & DCS-22 & Novocastra & $1: 10$ & Positive/negative & $>10 \%$ positive cells & Proliferating cells \\
\hline Cyclin E & $13^{\circ} 3$ & Novocastra & $1: 10$ & Positive/negative & $>10 \%$ positive cells & $\begin{array}{l}\text { TMA controls, proliferating } \\
\text { cells }\end{array}$ \\
\hline CDK1 & 1 & Transduction & 1:1500 & Positive/negative & $>10 \%$ positive cells & $\begin{array}{l}\text { TMA controls, proliferating } \\
\text { cells }\end{array}$ \\
\hline CDK2 & $8 \mathrm{D} 4$ & NeoMarkers & $1: 500$ & Positive/negative & $>10 \%$ positive cells & $\begin{array}{l}\text { TMA controls, proliferating } \\
\text { cells }\end{array}$ \\
\hline CDK4 & 35.1 & Chemicon & $1: 10$ & Positive/negative & $>10 \%$ positive cells & TMA controls \\
\hline CDK6 & K6.83 & Chemicon & $1: 10$ & Positive/negative & $>10 \%$ positive cells & TMA controls \\
\hline P21 & EA10 & Oncogene & $1: 50$ & Positive/negative & $>10 \%$ neoplastic cells & Scattered GC \\
\hline P16 & Polyclonal & Santa Cruz & $1: 50$ & High/low & $>10 \%$ positive cells & Normal cells \\
\hline P27 & 57 & Transduction & 1:1000 & High/low & $>10 \%$ positive cells & Resting lymphoid cells \\
\hline Ki67 & MIB 1 & DAKO & $1: 100$ & High/low & $>20 \%$ positive cells & Proliferating cells \\
\hline P53 & DO-7 & Novocastra & $1: 50$ & Positive/negative & $>50 \%$ positive cells & Scattered GC cells \\
\hline Hdm2 & IF2(mdm2) & Oncogene & $1: 10$ & High/low & $>10 \%$ positive cells & Macrophages \\
\hline CD3 & F7.2.38 & DAKO & $1: 25$ & Positive/negative & Any tumoral cell & Reactive lymphocyte \\
\hline P18 & B9 & Santa Cruz & $1: 150$ & High/low & $>10 \%$ positive cells & Normal cells \\
\hline $\mathrm{p}-\mathrm{I} \kappa \mathrm{B} \alpha$ & $\begin{array}{l}1118 \\
\text { ssc9965 }\end{array}$ & Santa Cruz & $1: 150$ & Positive/negative & $\begin{array}{l}>10 \% \text { (nucleus and } \\
\text { cytoplasm) }\end{array}$ & Normal cells \\
\hline
\end{tabular}

$\mathrm{GC}=$ germinal center.

\section{In Situ Detection of Epstein-Barr Virus and Apoptosis}

EBER in situ hybridization was performed using standard procedures and with the appropriate control tissue. Epstein-Barr virus (EBV) was detected by ISH with fluorescein-conjugated EpsteinBarr virus (EBER) PNA probe (DAKO, Glostrup, Denmark). Cases were considered EBV positive when nuclear positivity was present in a majority of neoplastic cells.

Apoptosis was detected using the ApopTag Peroxidase In Situ Apoptosis Detection Kit (Intergen, Oxford, UK), based on the TUNEL method. Briefly, tissue-microarray sections were pretreated with proteinase $\mathrm{K}$ for $15 \mathrm{~min}$, incubated with TdT enzyme for $1 \mathrm{~h}$ at $37^{\circ} \mathrm{C}$ and then with antidigoxigenin peroxidase conjugate for $1 \mathrm{~h}$. Color was developed with $3,3^{\prime}$ diaminobenzidine tetrahydrochloride (10 min) and counterstained with hematoxylin.

The reproducibility of the results was confirmed by comparing restricted lymphoid cell differentiation (CD20, CD3, CD138, CD79a, bcl6, and CD5) and
EBER-ISH marker results with those obtained from the original whole section for ten selected cases.

\section{Fluorescent In Situ Hybridization Study}

Tissue array sections from paraffin-embedded tissue were heated for $4 \mathrm{~h}$ at $62^{\circ} \mathrm{C}$ and immediately deparaffinized in two rinses of $100 \%$ xylene for 10 min each. The slides were then treated with $0.3 \mathrm{M}$ sodium chloride and $0.03 \mathrm{M}$ sodium citrate for $20 \mathrm{~min}$ at $80^{\circ} \mathrm{C}$, and with $0.05 \mathrm{mg} / \mathrm{ml}$ proteinase for $10 \mathrm{~min}$ at $37^{\circ} \mathrm{C}$. For $\mathrm{t}(11 ; 18)(\mathrm{q} 21 ; \mathrm{q} 21)$ detection, we used LSI API2/MALT1 t(11;18)(q21;q21) dual-color, dual-fusion translocation probe, and for $\mathrm{t}(14 ; 18)$ (q32;q21) we used LSI IGH/MALT1 t(14;18)(q32;q21) dual-color, dual-fusion translocation probe.

The cutoff value for the diagnosis of rearrangement involving $I G H$ and MALT1 was $5.3 \%$, which is above the mean percentage of cells with a falsepositive signal plus three s.d., as assessed in tissue from reactive tonsils present in TMA. Moreover, IGH 
dual-color break-apart rearrangement probes (Vysis Inc., Downers Grove, IL, USA) were applied to cells of all $\mathrm{t}(14 ; 18)(\mathrm{q} 32 ; \mathrm{q} 21)$-positive lymphomas to confirm the translocation. The Spectrum Green-labeled LSI IGVH probe covers the entire IGH variable region, while the Spectrum Orange-labeled probe lies completely $3^{\prime}$ to the $I G H$ locus. As a result of this probe design, any translocation with a breakpoint at the J segments, or within switch sequences, should produce separate orange and green signals. Additionally, FISH with centromere-specific probes for chromosome 18 (Vysis) was performed in all cases. The appropriate probe mix $(10 \mu \mathrm{l})$ was applied to the tissue sections and covered with a coverslip. Both probe and target DNA were simultaneously denatured at $75^{\circ} \mathrm{C}$ for $5 \mathrm{~min}$ and incubated overnight at $37^{\circ} \mathrm{C}$ using the Hybrite System. Posthybridization washes were performed according to the rapidwash protocol' provided by Vysis. Slides were counterstained with $4^{\prime} 6$-diamidino-2-phenylindole 2HCl (DAPI). FISH was performed according to the manufacturer's instructions (Vysis). FISH data were collected using an Olympus BX 61 fluorescence microscope equipped with a cooled black-and-white camera controlled by the associated software (Olympus, Italy). ${ }^{23,24}$

\section{Statistical Analysis}

The Pearson's $\chi^{2}$ test was used, where appropriate, to establish whether there were any relationships between the frequencies of different markers included in this study. Differences were considered to be significant for values of $P<0.05$.

Overall survival (OS) and failure-free survival (FFS) curves were calculated using the KaplanMeier method. Statistical significance of associations between individual variables and OS and FFS were determined using the log-rank test. All statistical analyses were performed using the SPSS 98 v.12 program.

OS was defined as the time from diagnosis (first biopsy) to death by any cause, or until the most recent follow-up. Moreover, taking into account the long-term survival observed in many of these cases and the existence of disease-unrelated deaths, disease-specific OS was also recorded. FFS was measured as the time from diagnosis to the occurrence of progression, relapse after complete remission, or death from any cause. FFS had a value of zero for patients who did not achieve complete remission.

\section{Results}

\section{Clinical Findings}

The main clinical characteristics of MALT and nonMALT OABL cases are set out in Table 2. The MALT lymphoma group was comprised of 39 cases $(21$ females and 18 males) with a mean age of 62 years (ranging from 27 to 84 years), and with 26 patients older than 59 years. The orbital region was involved in 35 cases (in particular, the lachrymal gland was infiltrated in 9/35 cases), the conjunctival mucosa in three cases, and the eyelid in one case. Bone marrow involvement was observed in four cases. Standard imaging studies, including ultrasonography and CT scan revealed no other locations in any of the cases.

Twelve of the 39 cases were studied serologically for the presence of infection by hepatitis $C$ virus (HCV) or hepatitis B virus. Six cases were found to be serum positive for HCV.

Therapy was heterogeneous, the patients being treated in accordance with their clinical stage, disease aggressiveness, age, and the status of knowledge over the last 20 years. Radiotherapy was standard, either alone (16/39 cases) or in conjunction with chemotherapy (6/39 cases). Statistical analysis of our series revealed no significant differences between these therapeutic approaches.

Relapse or persistence of local disease was observed in 13 cases. Relapse was recorded at the same site of origin in seven cases, and in the contralateral orbital region in two cases. Disease persisted after therapy in two cases. Dissemination was recorded in three cases: to loco-regional lymph nodes in two cases, and to the ovary in the third.

The mean OS in the series was 58 months (range from 6 to 215 months). The mean disease-specific OS, recorded in two cases, was 33 months, and the mean FFS was 28 months (range from 0 to 74 months). At the end of follow-up 24 patients were alive without disease, eight were alive with disease, two had died from causes attributable to the disease and five had died from causes unrelated to the disease.

\section{Main Morphological and Immunohistochemical Features of MALT OABLs}

Tumoral biopsy revealed a diffuse or vaguely nodular pattern of growth, with rare residual follicles in 10/39 cases, clearly highlighted by follicular dendritic cell staining (CD23 antibody). The neoplasia was mostly constituted by marginalzone cells (monocytoid- and centrocyte types) with interspersed lymphoplasmacytoid cells; lymphoplasmacytoid cell prevalence was recorded in two cases only. A low proportion (5-10\%) of scattered centroblast- and immunoblast-like cells was present in 24 cases $(61 \%)$. No cases with clusters of more than 20 large cells were observed (Figure 1).

Standard immunohistochemical staining showed pan-B markers in all cases (CD20 and CD79a), and negativity for germinal-center markers (CD10 or bcl6). Expression of CD43 (12/36) was variable. No positivity of neoplastic cells was observed for CD5 and CD23. Light-chain restriction was revealed in 33 cases; in particular, 25/34 showed kappa-chain restriction and 9/34 lambda-chain restriction. 
Table 2 Main clinicopathological features of patients

\begin{tabular}{|c|c|c|c|c|c|c|c|c|c|c|c|c|c|c|c|c|c|}
\hline Case no. & Sex & Age & Site & $\begin{array}{l}\text { Histology/cytotype } \\
\text { prevalence }\end{array}$ & $\begin{array}{l}\text { Bone } \\
\text { marrow }\end{array}$ & $\mathrm{HCV}$ & $E B E R$ & Therapy & $\begin{array}{l}\text { Relapse } \\
\text { (months } \\
\text { since } \\
\text { diagnosis) }\end{array}$ & $\begin{array}{l}\text { Systemic } \\
\text { progression } \\
\text { (months from } \\
\text { diagnosis) }\end{array}$ & $\begin{array}{l}\text { Follow-up time } \\
\text { (months since } \\
\text { diagnosis) }\end{array}$ & $L C$ & $C D 38$ & MUM1 & $C D 43$ & $\begin{array}{l}\text { Light-chain } \\
\text { restriction }\end{array}$ & Status \\
\hline
\end{tabular}

\begin{tabular}{|c|c|c|c|c|c|c|c|c|c|c|c|c|c|c|c|c|c|}
\hline 1 & M & 68 & $\mathrm{O}$ & MALT, Mz & - & ND & - & WW & NO & NO & 173 & No & - & - & - & $\Lambda$ & A \\
\hline 2 & M & 58 & $\mathrm{O}$ & MALT, Mz & - & ND & - & $\mathrm{CT}+\mathrm{RT}$ & Yes (69) & NO & 213 & No & - & - & - & $\Lambda$ & DO \\
\hline 3 & M & 76 & $\mathrm{O}$ & MALT, Mz & - & ND & - & CT & NO & NO & 215 & No & - & - & - & No & DO \\
\hline 4 & $\mathrm{~F}$ & 27 & $\mathrm{O}$ & MALT, Mz & - & ND & - & CT & Yes (54) & $\mathrm{Y}$ & 6 & Yes & - & - & + & $\kappa$ & $\mathrm{D}$ \\
\hline 5 & $\mathrm{~F}$ & 44 & $\mathrm{O}$ & MALT, Mz & - & ND & - & RT & NO & NO & 138 & No & - & - & - & No & A \\
\hline 6 & M & 75 & $\mathrm{O}$ & MALT, Mz & - & ND & - & WW & NO & NO & 20 & No & - & - & + & $\kappa$ & DO \\
\hline 7 & $\mathrm{~F}$ & 65 & $\mathrm{O}$ & MALT, Mz & - & ND & - & RT & Yes (7) & NO & 163 & No & - & - & + & $\Lambda$ & AWD \\
\hline 8 & M & 66 & C & MALT, Mz & - & ND & - & WW & NO & NO & 53 & No & - & - & - & $\kappa$ & DO \\
\hline 9 & $\mathrm{~F}$ & 83 & $\mathrm{O}$ & MALT, Mz & - & ND & - & WW & NO & NO & 24 & Yes & - & - & + & $\kappa$ & DO \\
\hline 10 & $\mathrm{~F}$ & 61 & $\mathrm{O}$ & MALT, Mz & ND & ND & - & WW & Yes (17) & $\mathrm{Y}$ & 147 & No & - & - & - & $\kappa$ & A \\
\hline 11 & $\mathrm{~F}$ & 37 & $\mathrm{O}$ & MALT, Mz & - & ND & - & WW & Yes (74) & NO & 138 & No & - & - & + & $\kappa$ & A \\
\hline 12 & $\mathrm{~F}$ & 66 & $\mathrm{O}$ & MALT, Mz & - & + & - & RT & NO & NO & 81 & No & - & - & + & $\kappa$ & A \\
\hline 13 & $\mathrm{~F}$ & 54 & $\mathrm{O}$ & MALT, Mz & - & - & - & $\mathrm{CT}+\mathrm{RT}$ & NO & NO & 104 & Yes & + & + & - & $\kappa$ & A \\
\hline 14 & M & 67 & C & MALT, Mz & - & ND & - & RT & NO & NO & 105 & No & - & - & - & $\Lambda$ & A \\
\hline 15 & M & 49 & $\mathrm{O}$ & MALT, Mz & - & ND & - & RT & NO & NO & 94 & Yes & - & - & + & $\Lambda$ & A \\
\hline 16 & M & 64 & $\mathrm{O}$ & MALT, Mz & - & ND & - & WW & Yes (13) & NO & 78 & No & - & - & + & $\kappa$ & AWD \\
\hline 17 & M & 65 & $\mathrm{O}$ & MALT, Mz & - & + & - & RT & NO & NO & 61 & No & - & - & - & $\kappa$ & A \\
\hline 18 & $\mathrm{~F}$ & 67 & $\mathrm{O}$ & MALT, Mz & ND & ND & - & $\mathrm{CT}+\mathrm{RT}$ & NO & NO & 6 & Yes & - & - & - & $\kappa$ & A \\
\hline 19 & $\mathrm{M}$ & 79 & $\mathrm{O}$ & MALT, Mz & - & - & - & WW & Yes (12) & $\mathrm{Y}$ & 47 & No & - & - & ND & $\kappa$ & AWD \\
\hline 20 & $\mathrm{~F}$ & 74 & $\mathrm{O}$ & MALT, Mz & - & + & - & WW & Yes (50) & $\mathrm{Y}$ & 51 & Yes & + & - & - & $\kappa$ & AWD \\
\hline 21 & $\mathrm{~F}$ & 76 & $\mathrm{O}$ & MALT, Mz & - & ND & - & WW & Yes (35) & $\mathrm{Y}$ & 35 & No & - & - & - & $\kappa$ & AWD \\
\hline 22 & $\mathrm{~F}$ & 78 & $\mathrm{O}$ & MALT, Mz & ND & ND & - & RT & NO & NO & 6 & Yes & - & - & - & No & A \\
\hline 23 & $\mathrm{~F}$ & 55 & $\mathrm{O}$ & MALT, Mz & + & - & - & $\mathrm{CT}+\mathrm{RT}$ & NO & NO & 6 & No & - & - & ND & $\Lambda$ & A \\
\hline 24 & M & 62 & C & MALT, Mz & + & - & - & $\mathrm{CT}+\mathrm{RT}$ & NO & NO & 32 & Yes & - & - & - & $\Lambda$ & A \\
\hline 25 & M & 46 & $\mathrm{O}$ & MALT, Mz & ND & ND & - & RT & NO & NO & 6 & No & - & - & - & No & A \\
\hline 26 & $\mathrm{~F}$ & 50 & $\mathrm{O}$ & MALT, Mz & ND & ND & - & RT & NO & NO & 6 & Yes & - & - & + & $\kappa$ & A \\
\hline 27 & $\mathrm{~F}$ & 78 & $\mathrm{O}$ & MALT, PL & ND & ND & - & RT & NO & NO & 6 & No & + & + & + & $\kappa$ & A \\
\hline 28 & $\mathrm{~F}$ & 30 & $\mathrm{O}$ & MALT, Mz & - & - & - & WW & NO & NO & 27 & Yes & - & - & - & $\kappa$ & A \\
\hline 29 & $\mathrm{M}$ & 77 & $\mathrm{O}$ & MALT, Mz & ND & + & - & RT & NO & NO & 8 & No & + & + & - & $\kappa$ & A \\
\hline 30 & $\mathrm{~F}$ & 55 & $\mathrm{P}$ & MALT, Mz & - & ND & - & RT & Yes (12) & NO & 25 & No & + & - & - & $\Lambda$ & A \\
\hline 31 & M & 70 & $\mathrm{O}$ & MALT, Mz & - & ND & - & WW & NO & NO & 22 & Yes & + & - & - & $\Lambda$ & A \\
\hline 32 & $\mathrm{~F}$ & 69 & $\mathrm{O}$ & MALT, Mz & + & ND & - & $\mathrm{CT}+\mathrm{RT}$ & NO & NO & 11 & No & - & - & ND & $\kappa$ & AWD \\
\hline 33 & $\mathrm{M}$ & 78 & $\mathrm{O}$ & MALT, Mz & - & ND & - & RT & NO & NO & 21 & No & + & - & + & $\kappa$ & A \\
\hline 34 & M & 69 & $\mathrm{O}$ & MALT, Mz & - & ND & - & CT & Yes (5) & $\mathrm{Y}$ & 7 & Yes & - & - & - & $\kappa$ & D \\
\hline 35 & $\mathrm{~F}$ & 84 & $\mathrm{O}$ & MALT, PL & - & + & - & RT & Yes (16) & NO & 18 & Yes & + & + & - & $\kappa$ & AWD \\
\hline 36 & $\mathrm{~F}$ & 60 & $\mathrm{O}$ & MALT, Mz & + & + & - & CT & NO & NO & 18 & Yes & - & - & + & $\kappa$ & A \\
\hline 37 & M & 65 & $\mathrm{O}$ & MALT, Mz & - & ND & - & CT & NO & $\mathrm{Y}(0)$ & 15 & Yes & - & - & - & ND & AWD \\
\hline 38 & $\mathrm{~F}$ & 37 & $\mathrm{O}$ & MALT, Mz & - & - & - & RT & NO & NO & 12 & No & - & - & - & $\kappa$ & A \\
\hline 39 & M & 42 & $\mathrm{O}$ & MALT, Mz & - & ND & - & RT & NO & NO & 6 & No & + & - & - & $\kappa$ & A \\
\hline 40 & $\mathrm{~F}$ & 60 & $\mathrm{P}$ & FL & ND & ND & - & WW & Yes (12) & NO & 12 & & - & - & - & $\Lambda$ & $\mathrm{D}$ \\
\hline 41 & $\mathrm{~F}$ & 85 & $\mathrm{O}$ & FL & ND & ND & - & RT & NO & $\mathrm{Y}$ & 6 & & - & - & - & No & A \\
\hline 42 & M & 67 & $\mathrm{O}$ & FL & - & - & - & RT & Yes (36) & NO & 178 & & - & - & ND & No & A \\
\hline 43 & $\mathrm{~F}$ & 82 & $\mathrm{O}$ & DBCL & ND & + & - & $\mathrm{CT}+\mathrm{RT}$ & NO & NO & 13 & & + & + & - & $\Lambda$ & A \\
\hline 44 & $\mathrm{~F}$ & 82 & $\mathrm{P}$ & DBCL & - & ND & - & WW & NO & NO & 15 & & - & + & + & $\kappa$ & DO \\
\hline 45 & $\mathrm{~F}$ & 69 & $\mathrm{O}$ & DBCL & ND & ND & - & ND & NO & NO & 6 & & + & - & - & $\kappa$ & A \\
\hline 46 & M & 44 & $\mathrm{O}$ & DBCL & + & ND & - & RT & NO & NO & 38 & & - & - & - & $\Lambda$ & A \\
\hline 47 & $\mathrm{M}$ & 20 & $\mathrm{O}$ & Burkitt & - & - & + & CT & NO & NO & 115 & & - & - & - & $\kappa$ & A \\
\hline
\end{tabular}

$\mathrm{M}=$ male; $\mathrm{F}=$ female; $\mathrm{O}=$ orbit; $\mathrm{C}=$ conjunctiva; $\mathrm{L}=$ eyelid; $\mathrm{Mz}=$ marginal-zone type; $\mathrm{P}=$ plasmocytoid; $\mathrm{ND}=$ not determined; $\mathrm{WW}=$ watch and wait; $\mathrm{CT}=$ chemotherapy; $\mathrm{RT}=$ radiotherapy; $\mathrm{LC}=$ large cells; $\mathrm{A}=$ alive; $\mathrm{DO}=$ dead from other causes; $\mathrm{D}=$ dead; $\mathrm{AWD}=$ alive with disease. 

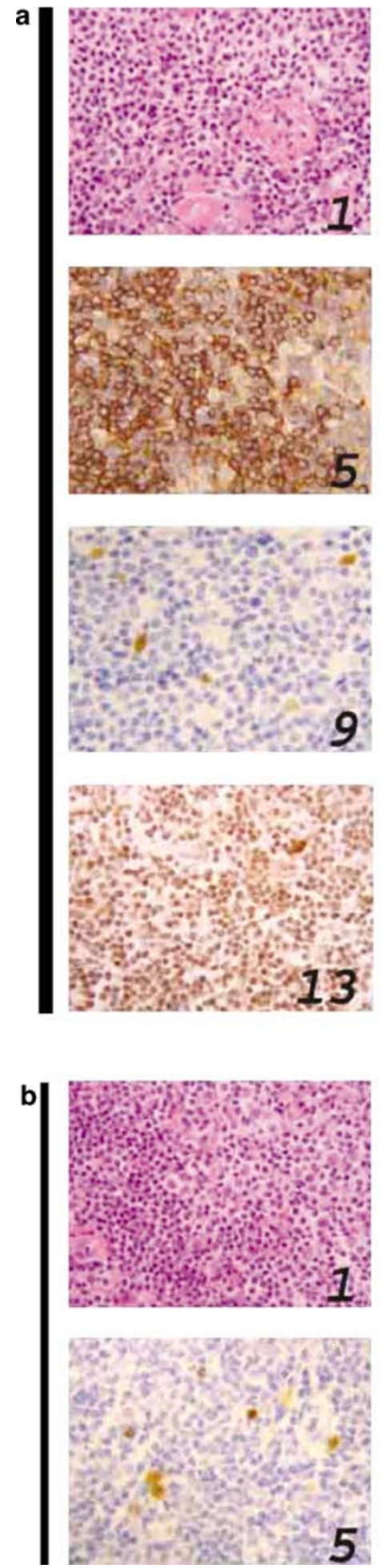
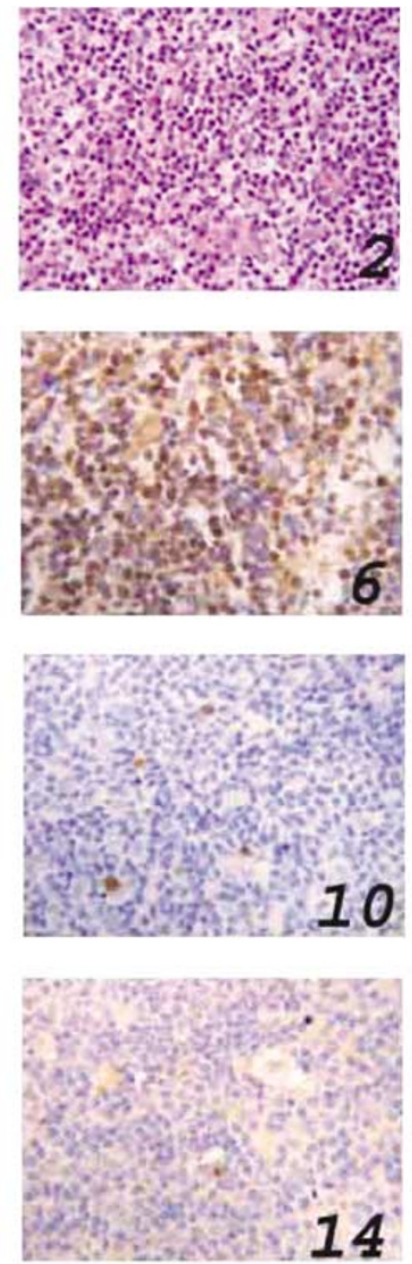
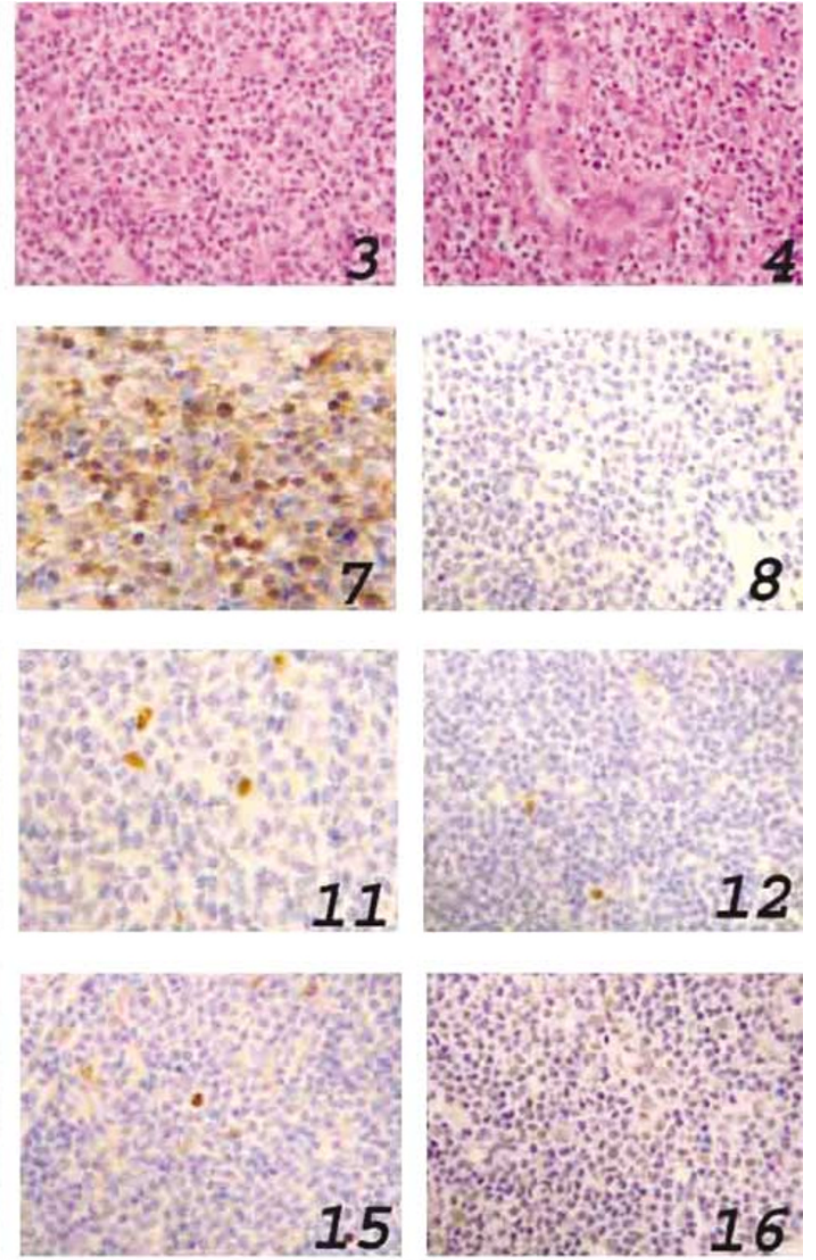
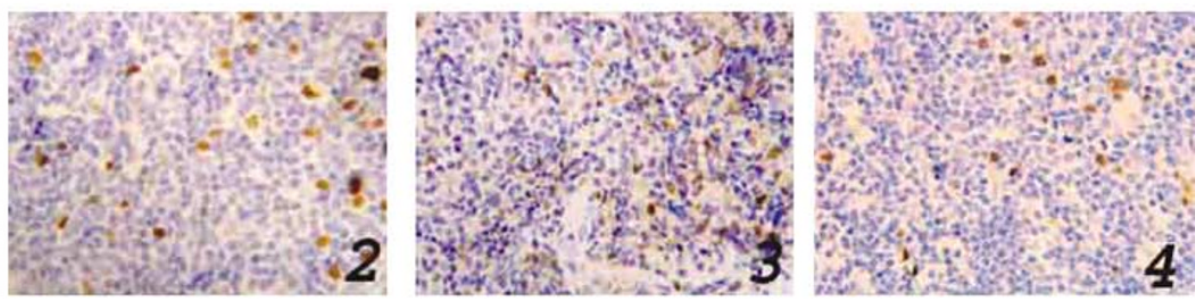

Figure 1 (a) Classical ocular adnexa MALT lymphoma; (1) prevalence of monocytoid cells (H\&E) ( $\times 63$ ); (2) prevalence of plasmocytoid cells (H\&E) ( $\times 63$ ); (3) prevalence of centrocytic cells $(\mathrm{H} \& \mathrm{E})(\times 63)$; (4) lymphoepithelial complex $(\times 63)$; (5) strong cytoplasmatic expression of Bcl10 ( $\times 63)$; (6) aberrant nuclear expression of Bcl10 ( $\times 100)$; (7) high nuclear expression of $\mathrm{p}-\mathrm{I} \kappa \mathrm{B} \alpha(\times 100)$; (8) absent expression of caspase 3 ( $\times 63$ ); (9) low expression of ki67 ( $\times 63)$; (10) low expression of cyclin E $(\times 63)$, (11) low expression of cyclin A ( $\times 63)$; (12) low expression of cyclin B1 $(\times 63)$; (13) normal expression of p16 $(\times 63)$; (14) low expression of Bcl- $\mathrm{X}_{\mathrm{L}}(\times 63)$; $(15)$ low expression of survivin ( $\times 63)$; (16) reduced TUNEL apoptotic index $(\times 63)$. (b) Ocular adnexa MALT lymphoma with large cell $(\times 63)$ : $(1)$ increased number of large cells (H\&E); (2) increased expression of ki67; (3) increased expression of cyclin E; (4) increased expression of cyclin A; (5) increased expression of cyclin B1; (6) reduced expression of p16; (7) increased expression of Bcl- $\mathrm{X}_{\mathrm{L}}$; (8) increased expression of survivin. 
Table 3 Expression of proteins involved in cell cycle

\begin{tabular}{|c|c|c|c|c|c|c|c|c|c|c|c|c|c|c|c|c|}
\hline Case & Histotype & Ki67 & $C D K 1$ & $C D K 2$ & $C D K 4$ & CDK6 & CусD1 & CусD3 & CусE & CicA & $P 16$ & P18 & P21 & $P 27$ & P53 & $H d m 2$ \\
\hline 1 & MALT & L & - & - & - & - & - & - & - & - & $\mathrm{H}$ & $\mathrm{L}$ & $\mathrm{L}$ & $\mathrm{H}$ & - & $\mathrm{L}$ \\
\hline 2 & MALT & $\mathrm{L}$ & - & - & - & - & - & - & - & - & $\mathrm{H}$ & ND & $\mathrm{L}$ & $\mathrm{H}$ & - & $\mathrm{L}$ \\
\hline 3 & MALT & $\mathrm{L}$ & + & - & + & - & - & - & - & - & $\mathrm{H}$ & $\mathrm{L}$ & $\mathrm{L}$ & $\mathrm{H}$ & - & L \\
\hline 4 & MALT & $\mathrm{L}$ & - & - & - & - & - & - & - & - & $\mathrm{L}$ & $\mathrm{H}$ & $\mathrm{L}$ & $\mathrm{L}$ & - & $\mathrm{L}$ \\
\hline 5 & MALT & $\mathrm{L}$ & - & - & - & + & - & - & - & - & $\mathrm{H}$ & ND & $\mathrm{L}$ & $\mathrm{H}$ & - & $\mathrm{L}$ \\
\hline 6 & MALT & $\mathrm{L}$ & - & - & - & - & - & - & - & - & $\mathrm{L}$ & $\mathrm{H}$ & $\mathrm{L}$ & $\mathrm{L}$ & - & L \\
\hline 7 & MALT & $\mathrm{L}$ & + & - & + & + & - & + & - & - & $\mathrm{H}$ & $\mathrm{H}$ & $\mathrm{L}$ & $\mathrm{H}$ & - & $\mathrm{H}$ \\
\hline 8 & MALT & $\mathrm{L}$ & - & - & - & + & - & - & - & - & $\mathrm{L}$ & $\mathrm{L}$ & L & $\mathrm{H}$ & - & $\mathrm{L}$ \\
\hline 9 & MALT & $\mathrm{L}$ & - & - & - & - & - & + & + & - & $\mathrm{H}$ & $\mathrm{L}$ & $\mathrm{L}$ & $\mathrm{L}$ & - & $\mathrm{L}$ \\
\hline 10 & MALT & $\mathrm{H}$ & - & - & - & + & - & - & - & + & $\mathrm{H}$ & $\mathrm{H}$ & $\mathrm{L}$ & $\mathrm{L}$ & - & $\mathrm{H}$ \\
\hline 11 & MALT & $\mathrm{L}$ & + & - & + & - & - & - & - & - & $\mathrm{L}$ & $\mathrm{L}$ & $\mathrm{L}$ & $\mathrm{H}$ & - & $\mathrm{L}$ \\
\hline 12 & MALT & $\mathrm{H}$ & + & - & - & + & - & + & - & - & $\mathrm{H}$ & $\mathrm{H}$ & $\mathrm{L}$ & $\mathrm{L}$ & - & $\mathrm{L}$ \\
\hline 13 & MALT & $\mathrm{H}$ & - & - & + & + & - & - & - & - & $\mathrm{L}$ & $\mathrm{H}$ & $\mathrm{L}$ & $\mathrm{L}$ & - & L \\
\hline 14 & MALT & $\mathrm{L}$ & + & - & - & - & - & - & - & - & $\mathrm{L}$ & $\mathrm{H}$ & $\mathrm{L}$ & $\mathrm{H}$ & - & $\mathrm{L}$ \\
\hline 15 & MALT & $\mathrm{L}$ & - & - & - & - & - & - & - & - & $\mathrm{L}$ & $\mathrm{H}$ & $\mathrm{L}$ & $\mathrm{H}$ & - & $\mathrm{L}$ \\
\hline 16 & MALT & $\mathrm{H}$ & + & - & - & - & - & - & - & - & $\mathrm{L}$ & $\mathrm{L}$ & $\mathrm{L}$ & $\mathrm{H}$ & - & L \\
\hline 17 & MALT & $\mathrm{L}$ & - & - & - & - & - & - & - & - & $\mathrm{H}$ & $\mathrm{L}$ & $\mathrm{L}$ & $\mathrm{H}$ & - & $\mathrm{L}$ \\
\hline 18 & MALT & $\mathrm{L}$ & - & - & - & - & - & - & - & - & $\mathrm{L}$ & ND & $\mathrm{L}$ & $\mathrm{L}$ & - & L \\
\hline 19 & MALT & $\mathrm{L}$ & - & - & - & - & - & - & - & - & $\mathrm{L}$ & ND & $\mathrm{L}$ & $\mathrm{L}$ & - & $\mathrm{L}$ \\
\hline 20 & MALT & $\mathrm{L}$ & - & - & - & - & - & - & - & - & $\mathrm{L}$ & ND & $\mathrm{L}$ & $\mathrm{L}$ & - & $\mathrm{L}$ \\
\hline 21 & MALT & $\mathrm{L}$ & - & - & + & + & - & - & - & - & $\mathrm{H}$ & $\mathrm{H}$ & $\mathrm{L}$ & $\mathrm{H}$ & - & $\mathrm{L}$ \\
\hline 22 & MALT & $\bar{L}$ & - & - & + & + & - & - & - & - & $\mathrm{H}$ & $\mathrm{H}$ & $\mathrm{H}$ & $\mathrm{H}$ & - & $\overline{\mathrm{H}}$ \\
\hline 23 & MALT & $\mathrm{L}$ & - & - & - & - & - & + & + & - & $\mathrm{H}$ & $\mathrm{L}$ & $\mathrm{L}$ & $\mathrm{H}$ & - & $\mathrm{L}$ \\
\hline 24 & MALT & $\mathrm{L}$ & - & - & - & - & - & - & + & - & $\mathrm{L}$ & $\mathrm{H}$ & $\mathrm{H}$ & $\mathrm{H}$ & - & $\mathrm{H}$ \\
\hline 25 & MALT & $\mathrm{L}$ & - & - & - & - & - & - & - & - & $\mathrm{L}$ & $\mathrm{H}$ & $\mathrm{L}$ & $\mathrm{H}$ & - & $\mathrm{L}$ \\
\hline 26 & MALT & $\mathrm{L}$ & - & - & + & + & - & - & - & - & $\mathrm{H}$ & $\mathrm{H}$ & $\mathrm{L}$ & $\mathrm{L}$ & - & $\mathrm{L}$ \\
\hline 27 & MALT & $\mathrm{H}$ & + & - & + & + & - & - & + & - & $\mathrm{H}$ & $\mathrm{H}$ & $\mathrm{L}$ & $\mathrm{H}$ & - & $\overline{\mathrm{H}}$ \\
\hline 28 & MALT & $\mathrm{L}$ & - & - & - & - & - & - & - & - & $\mathrm{L}$ & ND & $\mathrm{L}$ & $\mathrm{H}$ & - & $\mathrm{L}$ \\
\hline 29 & MALT & $\mathrm{H}$ & + & - & - & - & - & - & + & - & $\mathrm{L}$ & $\mathrm{H}$ & $\mathrm{L}$ & $\mathrm{H}$ & - & $\mathrm{H}$ \\
\hline 30 & MALT & $\mathrm{L}$ & - & - & - & - & - & - & - & - & $\mathrm{H}$ & $\mathrm{H}$ & $\mathrm{L}$ & $\mathrm{H}$ & - & $\mathrm{H}$ \\
\hline 31 & MALT & $\mathrm{H}$ & + & - & + & + & - & + & + & + & $\mathrm{L}$ & $\mathrm{H}$ & $\mathrm{L}$ & $\mathrm{H}$ & - & $\mathrm{H}$ \\
\hline 32 & MALT & $\mathrm{L}$ & - & - & - & - & - & - & - & - & $\bar{L}$ & ND & $\mathrm{L}$ & $\mathrm{L}$ & - & $\mathrm{L}$ \\
\hline 33 & MALT & $\mathrm{L}$ & - & - & - & - & - & - & - & - & $\mathrm{L}$ & ND & $\mathrm{L}$ & $\mathrm{L}$ & - & $\mathrm{L}$ \\
\hline 34 & MALT & $\mathrm{L}$ & - & - & - & - & - & + & - & - & $\mathrm{H}$ & $\mathrm{H}$ & $\mathrm{L}$ & $\mathrm{H}$ & - & $\mathrm{H}$ \\
\hline 35 & MALT & $\mathrm{H}$ & + & - & + & + & - & - & + & + & $\mathrm{L}$ & $\mathrm{H}$ & $\mathrm{H}$ & $\mathrm{H}$ & - & $\mathrm{H}$ \\
\hline 36 & MALT & $\mathrm{L}$ & - & - & + & + & - & - & - & + & $\mathrm{L}$ & $\mathrm{H}$ & $\mathrm{H}$ & $\mathrm{L}$ & - & $\mathrm{L}$ \\
\hline 37 & MALT & $\mathrm{H}$ & + & - & + & + & - & - & - & - & $\bar{L}$ & $\mathrm{H}$ & $\mathrm{L}$ & $\mathrm{H}$ & - & $\overline{\mathrm{H}}$ \\
\hline 38 & MALT & $\mathrm{L}$ & - & - & - & - & - & - & - & - & $\mathrm{H}$ & $\mathrm{L}$ & $\mathrm{L}$ & $\mathrm{L}$ & - & $\mathrm{L}$ \\
\hline 39 & MALT & $\mathrm{L}$ & - & - & - & - & - & - & - & - & $\mathrm{L}$ & $\mathrm{H}$ & $\mathrm{L}$ & $\mathrm{H}$ & - & $\mathrm{H}$ \\
\hline 40 & FL & $\mathrm{L}$ & - & - & + & + & - & - & + & + & $\mathrm{L}$ & $\mathrm{H}$ & $\mathrm{L}$ & $\mathrm{L}$ & - & $\mathrm{H}$ \\
\hline 41 & FL & $\mathrm{L}$ & - & - & - & - & - & - & - & - & $\mathrm{H}$ & $\mathrm{H}$ & $\mathrm{L}$ & $\mathrm{H}$ & - & $\mathrm{L}$ \\
\hline 42 & FL & $\mathrm{H}$ & + & - & - & - & - & - & - & - & $\mathrm{H}$ & $\mathrm{L}$ & $\mathrm{L}$ & $\mathrm{H}$ & - & $\mathrm{H}$ \\
\hline 43 & DBCL & $\mathrm{L}$ & - & - & + & + & - & - & + & + & $\mathrm{H}$ & $\mathrm{L}$ & $\mathrm{L}$ & $\mathrm{L}$ & + & $\mathrm{H}$ \\
\hline 44 & DBCL & $\mathrm{H}$ & + & - & + & + & - & + & - & + & $\mathrm{L}$ & $\mathrm{H}$ & $\mathrm{H}$ & $\mathrm{H}$ & - & $\mathrm{H}$ \\
\hline 45 & DBCL & $\mathrm{L}$ & - & - & + & + & - & - & - & - & $\mathrm{L}$ & $\mathrm{H}$ & $\mathrm{L}$ & $\mathrm{L}$ & - & $\mathrm{H}$ \\
\hline 46 & DBCL & $\mathrm{L}$ & - & - & - & - & - & - & ND & - & $\mathrm{H}$ & $\mathrm{L}$ & $\mathrm{L}$ & $\mathrm{L}$ & - & $\mathrm{L}$ \\
\hline 47 & Burkitt & $\mathrm{H}$ & + & - & + & + & - & + & + & + & $\mathrm{L}$ & $\mathrm{H}$ & $\mathrm{L}$ & $\mathrm{L}$ & + & $\mathrm{H}$ \\
\hline
\end{tabular}

$\mathrm{L}=$ low level; $\mathrm{H}=$ high level; $\mathrm{ND}=$ not determined.

In all, 9/39 cases showed CD38 positivity, which was associated with distinct plasma cell differentiation in two cases.

\section{Tissue-Microarrays Analysis}

The results of the TMA-immunohistochemical evaluations are reported in Tables 3-6.

In particular, and as expected for a low-grade lymphoma, in MALT OABLS, neoplastic cells of our series strongly expressed some markers involved in apoptosis regulation, such as bcl2 (39/39 cases), and diminished caspase 3 activity (38/39 cases). The group was divided considering the expression of cytoplasmic and nuclear p-I $\kappa \mathrm{B} \alpha$ (19/ 39), nuclear bcl10 (14/37), survivin (6/38) and Bcl- $X_{\mathrm{L}}$ (6/39).

Profiling of cell-cycle markers revealed a relatively low level of expression of protein related to $\mathrm{G} 2 / \mathrm{M}$ transition, that is, cyclin $\mathrm{A}$ (4/39 cases), cyclin B1 (4/39 cases), and CDK1 (11/39 cases). There were similar findings for proteins related to G1/S transition, that is, cyclin D1 (0/39), cyclin D3 (6/39), cyclin E (7/39), CDK2 (0/39), CDK4 (12/39), and CDK6 (14/39). Some abnormalities in the expression of CDK inhibitors were observed in the series. Thus, while p18 was uniformly expressed by neoplastic cells; p21 was strongly expressed by tumoral cells in four cases; loss of nuclear p27 was 
Table 4 Expression of proteins involved in apoptosis, and data for TUNEL, t(11;18)(q21;q21), and t(14;18)(q32;q21)

\begin{tabular}{|c|c|c|c|c|c|c|c|c|c|c|c|c|}
\hline Case & Histotype & Bcl2 & $B c l-X_{L}$ & Bax & Cytoplasmic Bcl1o & Nuclear Bcl10 & $p-I \kappa B \alpha$ & Caspase 3 & Survivin & TUNEL & $T(11 ; 18)$ & $T(14 ; 18)$ \\
\hline 1 & MALT & + & $\mathrm{L}$ & $\mathrm{H}$ & AW & ND & + & ND & $\mathrm{L}$ & ND & ND & + \\
\hline 2 & MALT & + & $\mathrm{L}$ & $\mathrm{H}$ & AW & ND & - & - & ND & ND & ND & ND \\
\hline 3 & MALT & + & $\mathrm{L}$ & $\mathrm{H}$ & AW & - & + & - & $\mathrm{L}$ & $\mathrm{L}$ & ND & ND \\
\hline 4 & MALT & + & $\mathrm{L}$ & $\mathrm{H}$ & AW & - & - & - & $\mathrm{L}$ & $\mathrm{H}$ & - & - \\
\hline 5 & MALT & + & $\mathrm{L}$ & $\mathrm{H}$ & AW & - & + & - & $\mathrm{L}$ & $\mathrm{H}$ & - & - \\
\hline 6 & MALT & + & $\mathrm{L}$ & $\mathrm{H}$ & AW & - & - & - & L & $\mathrm{H}$ & - & - \\
\hline 7 & MALT & + & $\mathrm{L}$ & $\mathrm{H}$ & $\mathrm{M}$ & + & + & - & $\mathrm{L}$ & $\mathrm{H}$ & - & - \\
\hline 8 & MALT & + & $\mathrm{L}$ & $\mathrm{H}$ & AW & + & + & - & $\mathrm{L}$ & $\mathrm{L}$ & - & - \\
\hline 9 & MALT & + & $\mathrm{L}$ & $\mathrm{H}$ & AW & - & - & - & $\mathrm{L}$ & $\mathrm{H}$ & - & - \\
\hline 10 & MALT & + & $\mathrm{L}$ & $\mathrm{H}$ & AW & + & - & - & $\mathrm{H}$ & $\mathrm{H}$ & - & - \\
\hline 11 & MALT & + & $\mathrm{L}$ & $\mathrm{H}$ & AW & - & + & _ & $\mathrm{L}$ & $\mathrm{H}$ & _ & _ \\
\hline 12 & MALT & + & $\mathrm{L}$ & $\mathrm{H}$ & AW & - & + & - & $\mathrm{L}$ & $\mathrm{H}$ & - & + \\
\hline 13 & MALT & + & $\mathrm{H}$ & $\mathrm{L}$ & AW & - & + & - & $\mathrm{H}$ & $\mathrm{H}$ & - & - \\
\hline 14 & MALT & + & $\mathrm{L}$ & $\mathrm{H}$ & $\mathrm{S}$ & - & + & - & $\mathrm{L}$ & $\mathrm{H}$ & - & + \\
\hline 15 & MALT & + & $\mathrm{H}$ & $\mathrm{H}$ & AW & - & + & - & $\mathrm{L}$ & $\mathrm{H}$ & - & - \\
\hline 16 & MALT & + & $\mathrm{L}$ & $\mathrm{H}$ & $\mathrm{M}$ & + & + & - & $\mathrm{L}$ & $\mathrm{H}$ & _ & _ \\
\hline 17 & MALT & + & $\mathrm{L}$ & $\mathrm{H}$ & AW & - & - & - & $\mathrm{L}$ & $\mathrm{H}$ & - & - \\
\hline 18 & MALT & + & $\mathrm{L}$ & $\mathrm{H}$ & AW & - & - & - & L & $\mathrm{H}$ & - & - \\
\hline 19 & MALT & + & $\mathrm{L}$ & $\mathrm{L}$ & AW & - & - & - & $\mathrm{L}$ & $\mathrm{H}$ & - & - \\
\hline 20 & MALT & + & $\mathrm{L}$ & $\mathrm{H}$ & AW & - & - & - & $\mathrm{L}$ & $\mathrm{L}$ & - & - \\
\hline 21 & MALT & + & $\mathrm{L}$ & $\mathrm{H}$ & AW & - & _ & _ & $\mathrm{L}$ & $\mathrm{H}$ & - & _ \\
\hline 22 & MALT & + & $\mathrm{L}$ & $\mathrm{H}$ & AW & - & + & - & $\mathrm{L}$ & $\mathrm{H}$ & - & - \\
\hline 23 & MALT & + & $\mathrm{L}$ & $\mathrm{H}$ & AW & - & - & - & $\mathrm{L}$ & $\mathrm{H}$ & - & - \\
\hline 24 & MALT & + & $\mathrm{L}$ & $\mathrm{H}$ & $\mathrm{M}$ & + & + & - & $\mathrm{L}$ & $\mathrm{H}$ & - & - \\
\hline 25 & MALT & + & $\mathrm{L}$ & $\mathrm{H}$ & AW & - & - & - & $\mathrm{L}$ & $\mathrm{H}$ & - & - \\
\hline 26 & MALT & + & $\mathrm{L}$ & $\mathrm{H}$ & AW & - & _ & _ & $\mathrm{L}$ & $\mathrm{H}$ & - & _ \\
\hline 27 & MALT & + & $\mathrm{L}$ & $\mathrm{H}$ & AW & + & + & - & $\mathrm{L}$ & $\mathrm{H}$ & - & - \\
\hline 28 & MALT & + & $\mathrm{L}$ & $\mathrm{L}$ & AW & - & - & - & $\mathrm{L}$ & $\mathrm{L}$ & - & - \\
\hline 29 & MALT & + & $\mathrm{H}$ & $\mathrm{L}$ & $\mathrm{S}$ & - & - & - & $\mathrm{H}$ & $\mathrm{H}$ & - & - \\
\hline 30 & MALT & + & $\mathrm{L}$ & $\mathrm{H}$ & $\mathrm{S}$ & - & + & - & $\mathrm{L}$ & $\mathrm{L}$ & - & + \\
\hline 31 & MALT & + & $\mathrm{H}$ & $\mathrm{H}$ & AW & + & + & + & $\mathrm{H}$ & $\mathrm{H}$ & - & + \\
\hline 32 & MALT & + & $\mathrm{L}$ & $\mathrm{L}$ & AW & - & - & - & $\mathrm{L}$ & $\mathrm{H}$ & - & - \\
\hline 33 & MALT & + & $\mathrm{L}$ & $\mathrm{L}$ & AW & - & - & - & $\mathrm{L}$ & $\mathrm{L}$ & - & - \\
\hline 34 & MALT & + & $\mathrm{L}$ & $\mathrm{H}$ & AW & + & - & - & $\mathrm{L}$ & $\mathrm{H}$ & - & - \\
\hline 35 & MALT & + & $\mathrm{H}$ & $\mathrm{H}$ & $\mathrm{M}$ & + & + & - & $\mathrm{H}$ & $\mathrm{L}$ & - & - \\
\hline 36 & MALT & + & $\mathrm{L}$ & $\mathrm{H}$ & AW & - & - & _ & $\mathrm{H}$ & $\mathrm{L}$ & - & _ \\
\hline 37 & MALT & + & $\mathrm{H}$ & $\mathrm{L}$ & AW & + & + & - & $\mathrm{L}$ & ND & - & - \\
\hline 38 & MALT & + & $\mathrm{L}$ & $\mathrm{L}$ & AW & - & - & - & $\mathrm{L}$ & $\mathrm{H}$ & - & - \\
\hline 39 & MALT & + & $\mathrm{L}$ & $\mathrm{L}$ & $\mathrm{M}$ & + & + & - & $\mathrm{L}$ & $\mathrm{H}$ & - & - \\
\hline 40 & $\mathrm{FL}$ & - & $\mathrm{H}$ & $\mathrm{H}$ & AW & - & - & + & $\mathrm{H}$ & $\mathrm{L}$ & - & - \\
\hline 41 & FL & - & $\mathrm{L}$ & $\mathrm{H}$ & $\mathrm{M}$ & - & - & + & $\mathrm{L}$ & $\mathrm{H}$ & - & - \\
\hline 42 & FL & - & $\mathrm{L}$ & $\mathrm{L}$ & $\mathrm{M}$ & + & - & - & $\mathrm{L}$ & $\mathrm{H}$ & - & - \\
\hline 43 & DBCL & - & $\mathrm{L}$ & $\mathrm{H}$ & $\mathrm{M}$ & - & - & + & $\mathrm{H}$ & $\mathrm{H}$ & - & - \\
\hline 44 & DBCL & - & $\mathrm{L}$ & $\mathrm{L}$ & $\mathrm{M}$ & - & + & + & $\mathrm{H}$ & $\mathrm{L}$ & - & - \\
\hline 45 & DBCL & + & $\mathrm{H}$ & $\mathrm{L}$ & $\mathrm{M}$ & + & + & - & $\mathrm{L}$ & $\mathrm{H}$ & - & - \\
\hline 46 & DBCL & + & $\mathrm{L}$ & $\mathrm{H}$ & $\mathrm{M}$ & + & + & - & $\mathrm{H}$ & $\mathrm{H}$ & ND & ND \\
\hline 47 & Burkitt & - & $\mathrm{L}$ & $\mathrm{L}$ & $\mathrm{M}$ & - & + & + & $\mathrm{H}$ & ND & - & - \\
\hline
\end{tabular}

$\mathrm{L}=$ low level; $\mathrm{H}=$ high level; $\mathrm{ND}=$ not determined; $\mathrm{S}=$ strong; $\mathrm{M}=$ moderate; $\mathrm{AW}=$ absent/weak.

observed in 14 cases and loss of p16 in 22 cases (Figure 1).

TUNEL revealed a reduced apoptotic index with respect to normal nongerminal center lymphoid tissue in 8/36 cases (Figure 1). EBER expression was negative in $39 / 39$ cases.

The FISH study of $\mathrm{t}(11 ; 18)$ yielded negative results in all the cases examined, although $\mathrm{t}(14 ; 18)(\mathrm{q} 32 ; \mathrm{q} 21)$ was present in $5 / 37$ cases (Figure 2). The presence of $\mathrm{t}(3 ; 14)(\mathrm{p} 14.1 ; \mathrm{q} 32)$ was not assayed. ${ }^{11}$

\section{Relationship between Variables}

Pearson's exact test showed numerous significant associations between the variables examined.

\section{Cytological Type}

Among MALT lymphomas, lymphoplasmacytoid differentiation was significantly associated with a high level of expression of CD38 $(P=0.03)$, MUM1 $(P \approx 0.000)$, and cyclin E $(P=0.006)$, when compared with the cases with prevalent marginal-zone differentiation.

\section{Histological Progression}

Cases with a greater presence of large B-cells (more than $5 \%$ of centroblasts or immunoblasts) showed an increased expression of proteins related to cell cycle or apoptosis regulation, such as 
Table 5 Summary of expression of proteins

\begin{tabular}{|c|c|c|c|c|c|c|c|c|c|c|c|c|c|c|c|c|c|}
\hline Diagnosis & Cases no. & Large cells & CD38 & MUM1 & $C D 43$ & Light-chain restriction & Ki67 & $C D K 1$ & $C D K 2$ & $C D K 4$ & $C D K 6$ & CусD1 & СусD3 & СусE & СусA & P16 & $P 18$ \\
\hline MALT & 39 & $15 / 39$ & $9 / 39$ & $4 / 39$ & $12 / 36$ & $\begin{array}{c}25 \kappa \\
9 \lambda\end{array}$ & $\begin{array}{c}9 \mathrm{H} \\
30 \mathrm{~L}\end{array}$ & $11 / 39$ & $0 / 39$ & $12 / 39$ & $14 / 39$ & $0 / 39$ & $6 / 39$ & $7 / 39$ & $4 / 39$ & $\begin{array}{l}17 \mathrm{H} \\
22 \mathrm{~L}\end{array}$ & $\begin{array}{c}22 \mathrm{H} \\
9 \mathrm{~L}\end{array}$ \\
\hline Low non-MALT & 3 & & $0 / 3$ & $0 / 3$ & $0 / 2$ & $1 \lambda$ & $\begin{array}{l}1 \mathrm{H} \\
2 \mathrm{~L}\end{array}$ & $1 / 3$ & $0 / 3$ & $1 / 3$ & $1 / 3$ & $0 / 3$ & $0 / 3$ & $1 / 3$ & $1 / 3$ & $\begin{array}{l}2 \mathrm{H} \\
1 \mathrm{~L}\end{array}$ & $\begin{array}{l}2 \mathrm{H} \\
1 \mathrm{~L}\end{array}$ \\
\hline High non-MALT & 5 & & $2 / 5$ & $2 / 5$ & $1 / 5$ & $\begin{array}{l}3 \kappa \\
2 \lambda\end{array}$ & $\begin{array}{l}2 \mathrm{H} \\
3 \mathrm{~L}\end{array}$ & $2 / 5$ & $0 / 5$ & $4 / 5$ & $4 / 5$ & $0 / 5$ & $2 / 5$ & $2 / 4$ & $3 / 5$ & $\begin{array}{l}2 \mathrm{H} \\
3 \mathrm{~L}\end{array}$ & $\begin{array}{l}3 \mathrm{H} \\
2 \mathrm{~L}\end{array}$ \\
\hline
\end{tabular}

$\mathrm{L}=$ low level; $\mathrm{H}=$ high level.

Table 6 Summary of expression of proteins, and data for TUNEL, t(11;18)(q21;q21), and t(14;18)(q32;q21)

\begin{tabular}{|c|c|c|c|c|c|c|c|c|c|c|c|c|c|c|c|c|}
\hline Diagnosis & Cases no. & $P 21$ & $P 27$ & P53 & $H d m 2$ & Bcl2 & $B c l-X_{L}$ & $B a x$ & Cytoplasmatic bcl10 & Nuclear bcl1o & $p-I \kappa B \alpha$ & Caspase 3 & Survivin & TUNEL & $T(11 ; 18)$ & $T(14 ; 18)$ \\
\hline MALT & 39 & $\begin{array}{c}4 \mathrm{H} \\
35 \mathrm{~L}\end{array}$ & $\begin{array}{l}25 \mathrm{H} \\
14 \mathrm{~L}\end{array}$ & $0 / 39$ & $\begin{array}{l}12 \mathrm{H} \\
27 \mathrm{~L}\end{array}$ & $39 / 39$ & $\begin{array}{c}6 \mathrm{H} \\
33 \mathrm{~L}\end{array}$ & $\begin{array}{c}30 \mathrm{H} \\
9 \mathrm{~L}\end{array}$ & $\begin{array}{c}31 \mathrm{AW} \\
5 \mathrm{M} \\
3 \mathrm{~S}\end{array}$ & $11 / 37$ & 19/39 & $1 / 38$ & $\begin{array}{c}6 \mathrm{H} \\
32 \mathrm{~L}\end{array}$ & $\begin{array}{c}28 \mathrm{H} \\
8 \mathrm{~L}\end{array}$ & $0 / 36$ & $5 / 37$ \\
\hline Low non-MALT & 3 & $3 \mathrm{~L}$ & $\begin{array}{l}2 \mathrm{H} \\
1 \mathrm{~L}\end{array}$ & $0 / 3$ & $\begin{array}{l}2 \mathrm{H} \\
1 \mathrm{~L}\end{array}$ & $0 / 3$ & $\begin{array}{l}1 \mathrm{H} \\
2 \mathrm{~L}\end{array}$ & $\begin{array}{l}2 \mathrm{H} \\
1 \mathrm{~L}\end{array}$ & $\begin{array}{c}1 \mathrm{AW} \\
2 \mathrm{M}\end{array}$ & $1 / 3$ & $0 / 3$ & $2 / 3$ & $\begin{array}{l}1 \mathrm{H} \\
2 \mathrm{~L}\end{array}$ & $\begin{array}{l}2 \mathrm{H} \\
1 \mathrm{~L}\end{array}$ & $0 / 3$ & $0 / 3$ \\
\hline High non-MALT & 5 & $\begin{array}{l}1 \mathrm{H} \\
4 \mathrm{~L}\end{array}$ & $\begin{array}{l}1 \mathrm{H} \\
4 \mathrm{~L}\end{array}$ & $2 / 5$ & $\begin{array}{l}4 \mathrm{H} \\
1 \mathrm{~L}\end{array}$ & $2 / 5$ & $\begin{array}{l}1 \mathrm{H} \\
4 \mathrm{~L}\end{array}$ & $\begin{array}{l}2 \mathrm{H} \\
3 \mathrm{~L}\end{array}$ & $5 \mathrm{M}$ & $2 / 5$ & $4 / 5$ & $3 / 5$ & $\begin{array}{l}4 \mathrm{H} \\
1 \mathrm{~L}\end{array}$ & $\begin{array}{l}3 \mathrm{H} \\
1 \mathrm{~L}\end{array}$ & $0 / 4$ & $0 / 4$ \\
\hline
\end{tabular}

$\mathrm{L}=$ low level; $\mathrm{H}=$ high level; $\mathrm{S}=$ strong; $\mathrm{M}=$ moderate; $\mathrm{AW}=$ absent/weak. 


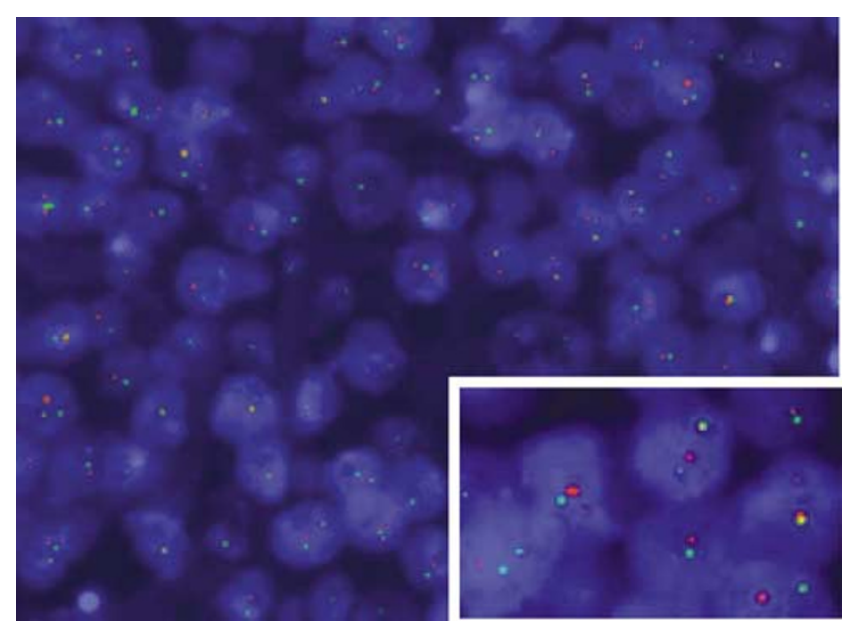

Figure 2 Two-color FISH to paraffin-embedded tissue for the detection of the translocation $\mathrm{t}(14 ; 18)$ (q32;q21). By using probes for IGH (green) and MALT1 (red), the translocation of MALT1 is demonstrated in this image, featuring fusion signals (yellow) in the interphase nuclei (detail in inset).

ki67 $(P=0.082)$, cyclin A $(P=0.077)$, cyclin B $(P=0.132)$, cyclin E $(P=0.075)$, survivin $(P=0.041)$, and Bcl- $_{\mathrm{L}}(P=0.041)$, and reduced expression of p16 $(P=0.042)$. All the cell-cycle markers also showed coregulated expression, as expected (Figure 1b).

\section{Apoptosis Regulation}

Nuclear bcl10 was associated with the expression of some proteins involved in cell-cycle progression, in particular Ki67 $(P<0.05)$, CDK1 $(P<0.05)$, CDK4 $(P<0.05)$, CDK6 $(P<0.05)$, cyclin A $(P=0.054)$, and cyclin D3 $(P=0.05)$. Moreover, it was associated with the expression of $\mathrm{p}-\mathrm{I} \kappa \mathrm{B} \alpha \quad(P<0.05), \mathrm{Hdm} 2$ $(P<0.001)$, p21 $(P=0.05)$, and the TUNEL index $(P<0.001)$.

The presence of $\mathrm{p}-\mathrm{I} \kappa \mathrm{B} \alpha$ was significantly associated with a high level of expression of CDK4 $(P<0.05)$, CDK6 $(P<0.001)$, p27 $(P<0.01)$, and with the presence of $t(14 ; 18) \quad(P<0.05)$. There was also a nearly significant trend relating $\mathrm{p}-\mathrm{I} \kappa \mathrm{B} \alpha$ with reduced TUNEL-apoptotic index $(P=0.059)$.

\section{MALT vs Non-MALT Lymphomas}

Comparing MALT with non-MALT lymphomas we observed in the latter group significantly greater expression of cyclin A $(P<0.05)$, cyclin $\mathrm{E}(P<0.05)$, and survivin $(P<0.01)$, and a trend towards greater expression of Hdm2 that just failed to reach significance $(P=0.051)$.

\section{Advanced-Stage Disease}

Finally, the advanced stage of the disease, when there is neoplastic infiltration of the bone marrow,

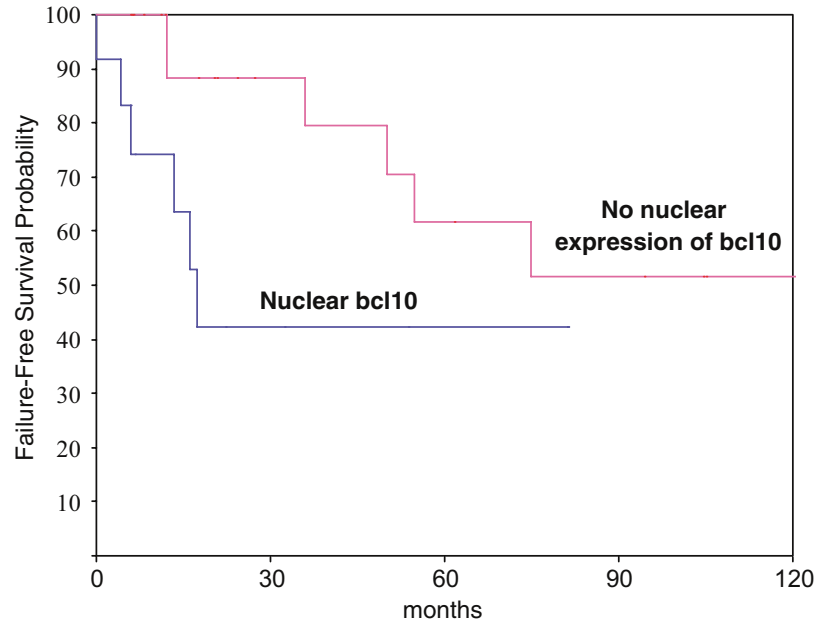

Figure 3 Kaplan-Meier curve of failure-free survival in relation to aberrant bcl10 nuclear expression $(P<0.0367)$.

was associated with a high degree of p21 expression $(P<0.01)$.

\section{HCV Serum Positivity}

No relation of HCV presence was observed with any of the clinicopathological parameters examined.

\section{Relationship with FFS and OS}

Survival analysis of MALT lymphomas using the Kaplan-Meier method revealed a shorter FFS for cases with nuclear expression of bcl10 $(P<0.05)$ (Figure 3).

Multivariate analysis revealed no significant association with FFS.

None of the variables examined showed associations with OS.

\section{Discussion}

MALT lymphomas in extranodal sites have mainly been characterized either by grouping all the different locations, or by following the features observed in the most characteristic locations, such as the gastrointestinal tract. Nevertheless, MALT lymphomas arising at sites other than the gastrointestinal tract display some specific morphological and molecular features. ${ }^{6,10}$ This has prompted us to characterize a large series of MALT lymphomas arising in the ocular adnexa with reference to a selected number of molecules that could provide information about the pathogenesis and biological predictors of this disease.

Historically, lymphomas arising in conjunctiva, orbit and eyelids have been grouped in a single category with similar therapeutic strategies and superimposable prognostic markers. ${ }^{1,2}$ MALT OABLs account for $24 \%$ of all MALT nongastric lymphomas, and are the third most frequent group 
of MALT lymphomas after the gastrointestinal and cutaneous groups. ${ }^{6}$

Our data confirm a slight prevalence of female patients, with preferential involvement of orbit localization with respect to other sites. ${ }^{2}$ Median age in this series was similar to that observed in other published series of MALT lymphomas. ${ }^{25}$

Most of the patients in this series have been treated with approaches aimed at eradicating local disease, either by surgery or radiotherapy. The relatively low proportion of patients treated with chemotherapy does not allow us to conclude which is the most successful approach. One striking feature was the relatively favorable clinical outcome, with only two cases of death attributable to the disease and 13 cases (30\%) showing local relapses, persistence, or systemic progression, with a mean time of 22 months from diagnosis.

HCV serum positivity was recorded in 5/10 MALT-type lymphoma cases. HCV is known to be a hepatotropic and lymphotropic virus, and it has been suggested that it may have a role in clonal B-cell proliferation. ${ }^{26}$ The relatively high prevalence $(50 \%)$ of HCV infection in this series supports the hypothesis that it may play a pathogenic role in this tumor.

Our series shows that the histological features of the tumor have no effect on clinical prognosis. In particular, large-cell presence is not significantly related to relapse and/or progression, in contrast to the findings in gastric MALT lymphoma. ${ }^{21}$

Deregulation of apoptosis seems to be a characteristic feature of this group of neoplasms, showing a diminished presence of active caspase 3 , which is a common end for different apoptotic pathways, and an increased expression of cytoplasmic and nuclear $\mathrm{p}-\mathrm{I} \kappa \mathrm{B} \alpha$, presumably related to $\mathrm{NF}-\kappa \mathrm{B}$ activity.

Alterations in the cell-cycle regulators were observed only in cases with histological progression, as indicated by an increased proportion of large B cells. These cases had a higher proliferation rate and level of expression of some molecules involved in cell-cycle regulation, such as cyclins A and $\mathrm{E}$. These are associated with an increase in the amount of several proteins, such as survivin and Bcl- $\mathrm{X}_{\mathrm{L}}$, that are involved in apoptosis control, making this group of lymphomas more similar to large B-cell lymphomas in our series.

In MALT lymphomas arising at gastrointestinal locations, it is claimed that MALT1, with or without bcl10 cooperation, activates the phosphorylation cascade, leading to $\mathrm{I} \kappa \mathrm{B}-\alpha$ phosphorylation. I $\kappa \mathrm{B}-\alpha$ is a physiological ligand of NF- $\kappa \mathrm{B}$ in the cytoplasm, whose phosphorylation permits the liberation and migration of NF- $\kappa$ B into the nucleus, where NF- $\kappa$ B plays its transcriptional role, upregulating the expression of antiapoptotic proteins. ${ }^{7,27-30}$ In MALT lymphoma, deregulation of the expression of MALT1 gene due to chromosomal translocations $\mathrm{t}(11 ; 18)(\mathrm{q} 21 ; \mathrm{q} 21)$ and $\mathrm{t}(14 ; 18)(\mathrm{q} 32 ; \mathrm{q} 21)$ seems to be one of the main pathogenic mechanisms leading to reduced apoptotic activity. ${ }^{12,15,22,31-33}$ In contrast to what has been described in gastric MALT lymphomas, our results did not indicate the presence of $\mathrm{t}(11 ; 18)$. This translocation has been extensively examined in gastric MALT lymphomas and is associated with cases of a more advanced stage or those lacking responses to Helicobacter pylori eradication. ${ }^{15,34}$ It occurs in $20-50 \%$ of gastric MALT lymphomas but the true incidence at other sites, with the exception of lung, is largely unknown..$^{22,24,31,33,34}$ In particular, the $t(11 ; 18)$ is reported as occurring in MALT lymphomas arising in the ocular adnexa at frequencies between 2.7 and $20 \% .^{10,33,34}$ The different incidence of this and other translocations in MALT lymphomas from distinct anatomical sites is probably linked to specific prelymphomatous conditions that lead to neoplastic transformation. Another translocation involving MALT1 and IgH genes, t(14;18) (q32;q21) has recently been described as occurring more frequently at sites considered to have a low incidence of $\mathrm{t}(11 ; 18)$, such as skin and orbit. ${ }^{12,33} \mathrm{In}$ our series $\mathrm{t}(14 ; 18)(\mathrm{q} 32 ; \mathrm{q} 21)$ was relatively more frequent and associated with $\mathrm{p}-\mathrm{I} \kappa \mathrm{B} \alpha$, thus confirming the link with NF- $\kappa \mathrm{B}$ activity. In this study, we have not assayed the presence of the recently described $\mathrm{t}(3 ; 14)(\mathrm{p} 14.1 ; \mathrm{q} 32) .{ }^{11}$

Another critical point in the pathogenesis of MALT lymphomas is the potential role of aberrant nuclear expression of bcl10. Under physiological conditions bcl10 plays a dual pro- and antiapoptotic role. ${ }^{12,15,31-33,35}$ The nuclear expression of bcl10 has been proposed as a surrogate of NF- $\kappa \mathrm{B}$ activation after $(11 ; 18)(q 21 ; q 21), t(1 ; 14)(p 22 ; q 32)$, while strong cytoplasmic expression has been linked with $\mathrm{t}(14 ; 18)(\mathrm{q} 32 ; \mathrm{q} 21) .^{7,12,22,35,36}$ Strikingly, our data show a clear association between nuclear bcl10, increased expression of $\mathrm{p}-\mathrm{I} \kappa \mathrm{B} \alpha$, and shorter time to failure. This, in addition to providing predictor parameters, suggests tentative therapeutic targets. Additionally, this series featured absent/weak cytoplasmic bcl10 expression compared with tonsil control in most cases, moderate bcl10 cytoplasmic expression in five cases, and strong cytoplasmic expression in three cases. A clear relation between this strong cytoplasmic expression and $t(14 ; 18)(q 32 ; q 21)$ was not observed, since only two of these three cases showed $\mathrm{t}(14 ; 18)(\mathrm{q} 32 ; \mathrm{q} 21)$ and three cases with $\mathrm{t}(14 ; 18)$ (q32;q21) showed only weak cytoplasmic bcl10 expression. The lack of association of aberrant nuclear and strong cytoplasmic bcl10 expression with any described translocation suggests the existence of additional chromosomal abnormalities that are yet to be characterized, such as the $\mathrm{t}(3 ; 14)(\mathrm{p} 14.1 ; \mathrm{q} 32)$.

In conclusion, tissue-microarray analysis shows that MALT OABLs represent a group mostly characterized by the deregulation of apoptosis. Alteration of apoptosis appears to be partially mediated by bcl10 shuttling to the nucleus, irrespective of $t(11 ; 18)$ presence, in contrast to what is observed 
in other MALT lymphomas. On the other hand, $\mathrm{t}(14 ; 18)(\mathrm{q} 32 ; \mathrm{q} 21)$, observed in a restricted number of cases, seems to affect apoptosis regulation by itself, because of its association with NFkB activity, as determined by $\mathrm{p}-\mathrm{I} \kappa \mathrm{B} \alpha$ expression.

\section{Acknowledgements}

This study was supported by grants from the Ministerio de Sanidad y Consumo (G03/179, PI051623) and the Ministerio de Ciencia y Tecnologia (HI2003-0035), Spain. We thank María Jesús Acuña and Raquel Pajares (Immunohistochemistry and Histology Unit, CNIO) for their expertise and excellent technical assistance with immunohistochemical assays.

\section{References}

1 Knowles DM, Jakobiec FA, McNally L, et al. Lymphoid hyperplasia and malignant lymphoma occurring in ocular adnexa (orbit, conjunctiva and eyelids) a prospective multiparametric analysis of 108 cases during 1977-1987. Hum Pathol 1990;21:959-973.

2 Knowles DM, Jakobiec FA. Ocular adnexa lymphoid neoplasms: clinical, histopathologic, electron microscopic and immunologic characteristics. Hum Pathol 1982;13:148-162.

3 Ferreri AJM, Guidoboni M, Ponzoni M, et al. Evidence for association between Chlamydia pittaci and ocular anexal lymphomas. J Natl Cancer Inst 2004;96: 586-594.

4 Mannami T, Yoshino T, Oshima K, et al. Clinical, histopathological and immunogenetic analysis of ocular adnexal lymphoproliferative disorders: characterization of MALT lymphoma and reactive lymphoid hyperplasia. Mod Pathol 2001;14:641-649.

5 McKelvie PA, McNab A, Francis IC, et al. Ocular adnexal lymphoproliferative disease: a series of 73 cases. Clin Exp Ophthalmol 2001;29:387-393.

6 Thieblemont C, Berger F, Dumontet C, et al. Mucosa associated lymphoid tissue lymphoma is a disseminated disease in one third of 158 patients analyzed. Blood 2000;95:802-806.

7 Sanchez-Beato M, Sanchez-Aguilera A, Piris MA. Cell cycle deregulation in B-cell lymphomas. Blood 2003;101:1220-1235.

8 Jaffe ES. Common threads of mucosa-associated lymphoid tissue lymphoma pathogenesis: from infection to translocation. J Natl Cancer Inst 2004;96:571-573.

9 Nakamura S, Yao T, Aoyagi K, et al. Helicobacter pylori and primary gastric lymphoma. A histopathologic and immunohistochemical analysis of 237 patients. Cancer 1997;79:3-11.

10 Takada S, Yoshino T, Taniwaki M, et al. Involvement of the chromosomal translocation $t(11 ; 18)$ in some mucosa-associated lymphoid tissue lymphomas and diffuse large B-cell lymphomas of the ocular adnexa. Evidence from multiplex reverse transcriptase-polymerase chain reaction and fluorescence in situ hybridization on using formalin-fixed, paraffin-embedded specimens. Mod Pathol 2003;16:445-452.
11 Streubel B, Vinatzer U, Lamprecht A, et al. $\mathrm{T}(3 ; 14)(\mathrm{p} 14.1 ; \mathrm{q} 32)$ involving IgH and FOXP1 is a novel recurrent chromosomal aberration in MALT lymphoma. Leukemia 2005;19:652-658.

12 Streubel B, Lamprecht A, Dierlamm J, et al. $\mathrm{T}(14 ; 18)(\mathrm{q} 32 ; \mathrm{q} 21)$ involving IGH and MALT1 is a frequent chromosomal aberration in MALT lymphoma. Blood 2003;101:2335-2339.

13 Uno $\mathrm{T}$, Isobe $\mathrm{K}$, Shikama $\mathrm{N}$, et al. Radiotherapy for extranodal, marginal zone, B cell lymphoma of mucosa-associated lymphoid tissue originating in ocular adnexa. A multiinstitutional, retrospective review of 50 patients. Cancer 2003;98:865-871.

14 Conconi A, Martinelli A, Thiéblemont C, et al. Clinical activity of rituximab in extranodal marginal zone B-cell lymphoma of MALT type. Blood 2003;102: 2741-2745.

15 Ye $\mathrm{H}$, Liu $\mathrm{H}$, Raderer $\mathrm{M}$, et al. High incidence of $\mathrm{t}(11 ; 18)$ (q21;q21) in Helicobacter pylori-negative gastric MALT Lymphoma. Blood 2003;101:2547-2550.

16 Zucca E, Cavalli F. Extranodal lymphoma. Ann Oncol 2000;11(Suppl 3):219-222.

17 Saez AI, Saez AJ, Artiga MJ, et al. Building an outcome predictor model for diffuse large B-cell lymphoma. Am J Pathol 2004;164:613-622.

18 Ruiz-Ballesteros E, Mollejo M, Rodriguez A, et al. Splenic marginal zone lymphoma. Proposal of new diagnostic and prognostic markers identified after tissue and cDNA microarray analysis. Blood 2005;106: 1831-1838.

19 Zinzani P, Dirnhofer S, Sabattini E, et al. Identification of outcome predictors in diffuse large B-cell lymphoma. Immunohistochemical profiling of homogeneously treated de novo tumors with nodal presentation on tissue micro-arrays. Haematologica 2005;90:341-347.

20 Sundram U, Kim Y, Mraz-Gernhard S, et al. Expression of the bcl-6 and MUM1/IRF4 proteins correlate with overall and disease-specific survival in patients with primary cutaneous large B-cell lymphoma: a tissue microarray study. J Cutaneous Pathol 2005;32: $227-234$.

21 De Jong D, Boot H, Van Heerde P, et al. Histological grading and gastric lymphoma: pre-treatment criteria and clinical relevance. Gastroenterology 1997;112: 1466-1474.

22 Ye $\mathrm{H}$, Gong L, Liu H, et al. MALT lymphoma with $\mathrm{t}(14 ; 18)$ (q32;q21)/iGH-MALT1 is characterized by strong cytoplasmatic MALT1 and bcl10 expression. J Pathol 2005;205:293-301.

23 Murga Penas EM, Hinz K, Roser K, et al. Translocations $t(11 ; 18)(q 21 ; q 21)$ and $t(14 ; 18)(q 32 ; q 21)$ are the main chromosomal abnormalities involving MLT/ MALT1 in MALT lymphomas. Leukemia 2003;17: 2225-2229.

24 Remstein ED, Kurtin PJ, Einerson RR, et al. Primary pulmonary MALT lymphomas show frequent and heterogeneous cytogenetic abnormalities, including aneuploidy and translocations involving API2 and MALT1 and IGH and MALT1. Leukemia 2004;18: 156-160.

25 Thieblemont C, Bastion Y, Berger F, et al. Mucosa associated lymphoid tissue gastrointestinal and nongastrointestinal lymphoma behaviour: analysis of 108 patients. J Clin Oncol 1997;15:1624-1630.

26 Silvestri F, Pipan C, Barillari G, et al. prevalence of hepatitis $\mathrm{C}$ virus infection in patients with lymphoproliferative disorders. Leukemia 1996;10:351-355. 
27 Liu Y, Dong W, Chen L, et al. Characterization of bcl10 as a potential transcriptional activator that interacts with general transcription factor TFIIB. Biochem Biophys Res Com 2004;320:1-6.

28 Ghosh S, May MJ, Kopp EB. NF-kB and Rel proteins: evolutionarily conserved mediators of immune responses. Annu Rev Immunol 1998;16:225-260.

29 Johnson C, Van Antwerp D, Hope TJ. An N-terminal nuclear export signal is required for the nucleocytoplasmic shuttling of IkBalpha. EMBO J 1999;18: 6682-6693.

30 Karin M, Ben-Neriah Y. Phosphorylation meets ubiquitination: the control of NF-kB activity. Annu Rev Immunol 2000;18:621-663.

31 Dierlamm J, Wlodarska I, Michaux L, et al. Genetic abnormalities in marginal zone B-cell lymphoma. Hematol Oncol 2000;18:1-13.

32 Liu H, Ye H, Dogan A, et al. T(11,18) (q21;q21) is associated with advanced mucosa-associated lym- phoid tissue lymphoma that expresses nuclear Bcl10. Blood 2001;98:1182-1187.

33 Streubel B, Klupp Simonitsch I, Mullauer L, et al. Variable frequencies of MALT lymphoma-associated genetic aberrations in MALT lymphomas of different sites. Leukemia 2004;18:1722-1726.

34 Ye H, Liu H, Attygalle A, et al. Variable frequencies of $t(11,18)$ (q21;q21) in MALT lymphomas of different sites: significant association with CagA strains of $H$. pylori in gastric lymphoma. Blood 2003;102:10121018.

35 Capello D, Gaidano G. Molecular pathophysiology of indolent lymphoma. Haematologica 2000;85: 195-201.

36 Kuo SH, Chen LT, Yeh KH, et al. Nuclear expression of bcl10 or nuclear factor kappa B predicts Helicobacter pylori-independent status of early-stage, high-grade gastric mucosa-associated lymphoid tissue lymphomas. J Clin Oncol 2004;22:3491-3497. 